\title{
Relationship between uric acid levels and risk of chronic kidney disease in a retrospective cohort of Brazilian workers
}

\author{
L.S.N. Chini ${ }^{1}$, L.I.S. Assis ${ }^{2}$ and J.R. Lugon ${ }^{3}$ \\ ${ }^{1}$ Divisão de Medicina Interna, Departamento de Medicina, Universidade Federal Fluminense, Niterói, RJ, Brasil \\ ${ }^{2}$ Universidade Federal do Estado do Rio de Janeiro, Rio de Janeiro, RJ, Brasil \\ ${ }^{3}$ Divisão de Nefrologia, Departamento de Medicina, Universidade Federal Fluminense, Niterói, RJ, Brasil
}

\begin{abstract}
Uric acid (UA) levels are increased in patients with kidney dysfunction. We analyzed the association between asymptomatic hyperuricemia and new-onset chronic kidney disease (CKD). A retrospective cohort study was designed to collect data from employees of an energy generation and distribution company in the city of Rio de Janeiro, Brazil, who had undergone the company's annual medical checkup from 2008 to 2014. People with $\leqslant 2$ years of follow-up, with baseline estimated glomerular filtration rate $\left(\right.$ eGFR) $<60 \mathrm{~mL} \cdot \mathrm{min}^{-1} \cdot\left(1.73 \mathrm{~m}^{2}\right)^{-1}$ or with incomplete data were excluded. The endpoint was defined as eGFR $<60 \mathrm{~mL} \cdot \min ^{-1} \cdot\left(1.73 \mathrm{~m}^{2}\right)^{-1}$ estimated through the chronic kidney disease epidemiology collaboration equation (CKD-EPI). The study included 1094 participants. The mean follow-up period was $5.05 \pm 1.05$ years and 44 participants exhibited new-onset CKD. The prevalence of hyperuricemia was $4.2 \%$. There was a significant inverse correlation between baseline serum levels of UA and baseline eGFR $(R=-0.21, P<0.001)$. Female gender $(\mathrm{OR}=4.00 ; 95 \% \mathrm{Cl}=1.92-8.29, \mathrm{P}<0.001)$ and age $(\mathrm{OR}=1.06 ; 95 \% \mathrm{Cl}=1.02-1.11$, $\mathrm{P}=0.004$ ) but not UA levels (OR=1.12; 95\%Cl=0.83-1.50; $\mathrm{P}=0.465)$ were associated with new-onset $\mathrm{CKD}$. Diabetes mellitus and body mass index were independent factors for fast progression $(\mathrm{OR}=2.17 ; 95 \% \mathrm{Cl}=1.24-3.80, \mathrm{P}=0.007$ and $\mathrm{OR}=1.04 ; 95 \% \mathrm{Cl}=1.01-1.07$; $\mathrm{P}=0.020$ ). These results did not support UA as an independent predictor for CKD progression in the studied population.
\end{abstract}

Key words: Chronic kidney disease; Hyperuricemia; Glomerular filtration rate

\section{Introduction}

Chronic kidney disease (CKD) is a worldwide public health problem and its management, by either dialysis or transplantation, imposes a considerable economic burden to health systems (1). Its prevalence is high and continues to increase, especially in developing countries (2). Studies have suggested that early diagnosis and treatment of modifiable CKD risk factors are important to prevent the progression to renal replacement therapy $(3,4)$. Established predictors for development of CKD include high blood pressure and diabetes mellitus $(5,6)$.

Uric acid (UA) is the end product of purine metabolism in humans, and its high serum levels, hyperuricemia, are classically related to the precipitation of crystals in the joints, leading to arthritis (7). There is increasing evidence of the association of hyperuricemia with hypertension and cardiovascular disease $(8,9)$. However, whether hyperuricemia is a predictor of CKD or only a consequence of reduced UA excretion is still not clear (10).

In recent years, a large number of observational studies have examined the potential relationship between hyperuricemia and development of CKD. These studies have shown conflicting results. Feig examined 12 epidemiology studies, finding a positive correlation in 8 and absence of association in 4 (11). Two meta-analysis published in 2014 favored the relationship when the follow-up period was long enough or when participants were middle-aged $(12,13)$. However, to date, this subject is still a matter of controversy (14). Therefore, the aim of the present study was to analyze the association between asymptomatic hyperuricemia and new-onset CKD in employees of an energy generation and distribution company in the city of Rio de Janeiro, Brazil.

\section{Material and Methods}

\section{Study population}

This was a retrospective cohort study. Data was collected from employees of an energy generation and distribution company in the city of Rio de Janeiro, Brazil, who had undergone the company's annual medical 
checkup from 2008 to 2014. The study population was composed of office workers in non-laborious activities during work hours. To certify that only cases of asymptomatic hyperuricemia were studied, participants with a history of gout attacks were excluded. Those with $\leqslant 2$ years of follow-up, with estimated glomerular filtration rate (eGFR) $<60 \mathrm{~mL} \cdot \mathrm{min}^{-1} \cdot\left(1.73 \mathrm{~m}^{2}\right)^{-1}$ in the first exam or with incomplete data were also excluded.

Sociodemographic information, physical examination data and biochemical analysis data were based on the participant's first year medical examination. A second result of serum creatinine was obtained from the last annual checkup.

\section{Disease definition}

Hyperuricemia was defined as a UA of $>6.0 \mathrm{mg} / \mathrm{dL}$ in women and $>7.0 \mathrm{mg} / \mathrm{dL}$ in men (15). CKD was defined as an eGFR $<60 \mathrm{~mL} \cdot \mathrm{min}^{-1} \cdot\left(1.73 \mathrm{~m}^{2}\right)^{-1}(10)$. The eGFR was estimated using the chronic kidney disease epidemiology collaboration equation (CKD-EPI) (16), as follows:

If female and serum creatinine $(\mathrm{sCr}) \leqslant 0.7 \mathrm{mg} / \mathrm{dL}$ : eGFR=144 $\times(\mathrm{sCr} / 0.7)^{-0.329} \times 0.993^{\text {age }}$;

If female and $\mathrm{sCr}>0.7 \mathrm{mg} / \mathrm{dL}:$ eGFR=144 $\times$ $(\mathrm{sCr} / 0.7)^{-1.209} \times 0.993^{\text {age }}$;

If male and $\mathrm{sCr} \leqslant 0.9 \mathrm{mg} / \mathrm{dL}:$ eGFR=141 $\times$ $(\mathrm{sCr} / 0.9)^{-0.411} \times 0.993^{\text {age }}$;

If male and $\mathrm{sCr}>0.9 \mathrm{mg} / \mathrm{dL}$ : eGFR=141 $\times$ $(\mathrm{sCr} / 0.9)^{-1.209} \times 0.993^{\text {age }}$.

Hypertension was defined as systolic blood pressure of $\geqslant 140 \mathrm{mmHg}$, diastolic blood pressure $\geqslant 90 \mathrm{mmHg}$ or current use of antihypertensive medication, according to the Seventh Report of the Joint National Committee on the Prevention, Detection, Evaluation, and Treatment of High Blood Pressure (17). The diagnosis of diabetes mellitus was defined as a fasting blood glucose level of at least $126 \mathrm{mg} / \mathrm{dL}$, or current use of glucose-lowering agents (18). Metabolic syndrome and its components were diagnosed employing the harmonizing definition. This required the presence of at least three of five parameters: increase waist circumference $(\geqslant 90 \mathrm{~cm}$ in men and $\geqslant 80 \mathrm{~cm}$ in women), triglyceride $\geqslant 150 \mathrm{mg} / \mathrm{dL}$ or treatment for hypertriglyceridemia, high density lipoprotein cholesterol (HDL-C) $<40 \mathrm{mg} / \mathrm{dL}$ for men and $<50 \mathrm{mg} / \mathrm{dL}$ for women or drug treatment for this abnormality, systolic blood pressure $\geqslant 130 \mathrm{mmHg}$ or diastolic blood pressure $\geqslant 85 \mathrm{mmHg}$ or treatment for high blood pressure and fasting glucose $\geqslant 100 \mathrm{mg} / \mathrm{dL}$ or treatment for high glucose (19).

Blood pressure was measured in the left arm in the sitting position, after $5 \mathrm{~min}$ at rest, using an aneroid sphygmomanometer with an accuracy of $5 \mathrm{mmHg}$. The first and fifth Korotkoff sounds were recorded, and the mean value of 3 measurements was used for analysis. Body weight was measured with light clothing and without shoes by an adjustable scale (Filizola, Brazil). Height was measured without shoes using a stadiometer to the nearest $0.1 \mathrm{~cm}$. The body mass index $(\mathrm{BMI})$ was calculated as the weight (in kilograms) divided by the square of the height (in meters). All measurements were taken by trained nurses.

Higher education was defined as a complete postsecondary education. Sedentary lifestyle was defined as doing irregular or no physical activity.

The biochemical analyses were performed in samples obtained after at least $12 \mathrm{~h}$ of fasting. The serum levels of fasting plasma glucose, creatinine, total cholesterol, HDL-C, and triglycerides were measured by enzymology using the automated chemistry analyzer Selectra-E (Wiener Lab, Argentina) or the Labimax 240 premium (Hirose Electronic System CO., Ltd., Japan). Serum UA was measured by an enzymatic method (Liquiform, Labtest, Brazil) with intra- and total variation coefficients of $0.82-0.97$ and $1.14-1.48 \%$, respectively.

\section{Statistical analysis}

Statistical analyses were conducted using the Statistical Package for Social Sciences version 18.0 (SPSS Inc., USA). The results of continuous variables are reported as mean and standard deviation if distribution was Gaussian, and alternatively as median and range if the distribution was not normal. Categorical variables are reported as frequencies. Comparisons between two groups were carried out by the unpaired $t$-test in case of normal distribution or, alternatively, by its nonparametric equivalent, the MannWhitney test. Pearson or Spearman correlation tests were used as appropriate. Logistic regression was used to test for association of independent variables with eGFR $<60 \mathrm{~mL} \cdot \mathrm{min}^{-1} \cdot\left(1.73 \mathrm{~m}^{2}\right)^{-1}$. $\mathrm{P}$ values less than 0.05 were considered significant.

\section{Ethical approval}

The study was conducted with the approval of the Research Ethical Committee of the Faculdade de Medicina, Universidade Federal Fluminense, Niterói, RJ, Brazil (CAAE: 44061515.7.0000.5243).

\section{Results}

From a total of 1413 participants, 1094 were selected for the final analysis (Figure 1). Of those excluded due to an insufficient follow-up, none developed eGFR below $60 \mathrm{~mL} \cdot \mathrm{min}^{-1} \cdot\left(1.73 \mathrm{~m}^{2}\right)^{-1}$. The mean follow-up period of the study population was $5.05 \pm 1.05$ years. Their baseline characteristics are shown in Table 1 . The mean age of patients was $48.7 \pm 8.8$ years. The participants were predominantly male and white, $12 \%$ were current smokers, and $4.2 \%$ had hyperuricemia. Sixty patients $(5.5 \%)$ were diabetic, with 33 diagnosed with diabetes mellitus by the start of the study and undergoing treatment. From those under treatment, $16(48 \%)$ had a fast blood glucose $<126 \mathrm{mg} / \mathrm{dL}$. There were 313 hypertensive patients $(28.6 \%), 153(49 \%)$ of them under treatment, from which $86(56.2 \%)$ had controlled blood pressure. Of note, $47.3 \%$ 


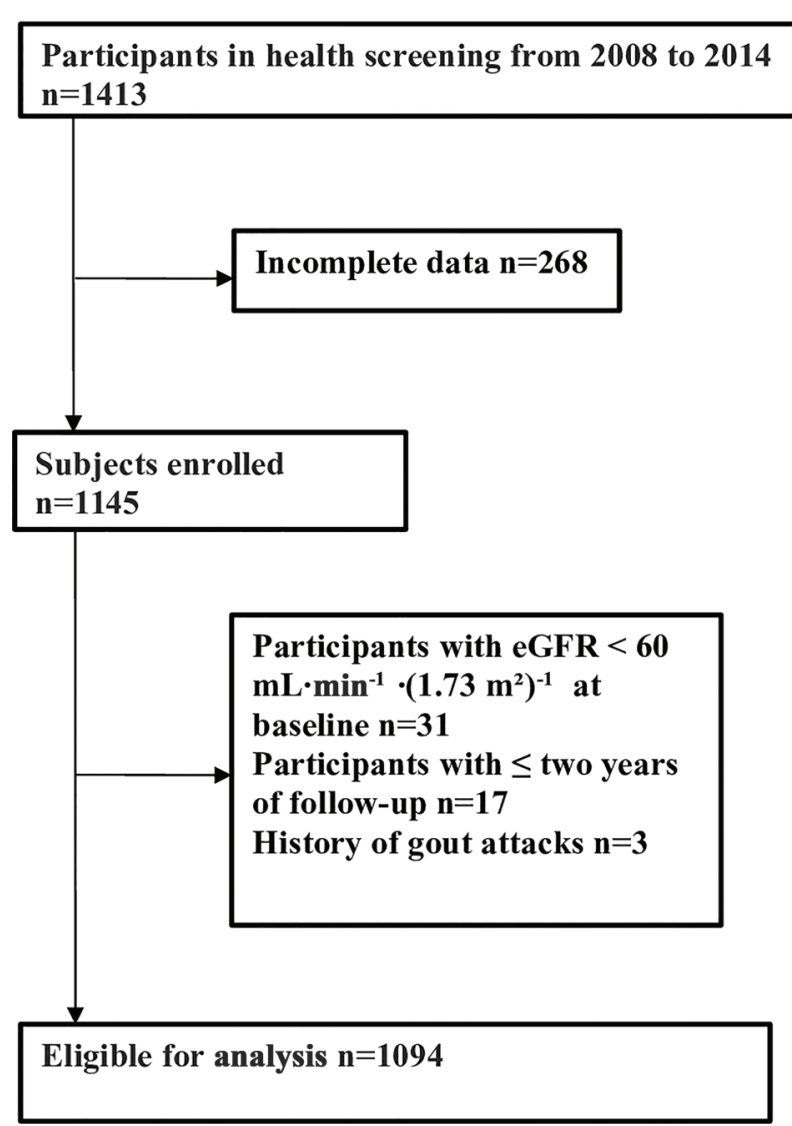

Figure 1. Selection of study participants.

of the sample had metabolic syndrome. Mean BMI was statistically higher in hyperuricemic participants and so did the systolic and diastolic blood pressure, serum levels of triglycerides, total cholesterol and creatinine (for creatinine the difference was restricted to males). As a consequence, the prevalence of metabolic syndrome in hyperuricemic patients was also higher. There was a weak but significant inverse correlation between baseline serum levels of UA and baseline eGFR $(R=-0.21$, $\mathrm{P}<0.001$ ).

The eGFR varied along the study from $105.6 \pm 14.8$ to $87.9 \pm 17.8 \mathrm{~mL} \cdot \mathrm{min}^{-1} \cdot\left(1.73 \mathrm{~m}^{2}\right)^{-1}(\mathrm{P}<0.001)$ resulting in a mean decline of $17.7 \pm 18.8 \mathrm{~mL} \cdot \mathrm{min}^{-1} \cdot\left(1.73 \mathrm{~m}^{2}\right)^{-1}$. The mean annual rate of progression was $3.5 \pm 4.3 \mathrm{~mL}$. $\mathrm{min}^{-1} \cdot\left(1.73 \mathrm{~m}^{2}\right)^{-1}$. Patients were classified according to the rate of progression, following a previous study (3). In $19.7 \%$ of cases no progression was observed; in $4.7 \%$ the annual rate of progression was between zero to $1 \mathrm{~mL} \cdot \min ^{-1} \cdot\left(1.73 \mathrm{~m}^{2}\right)^{-1}$, characterizing a mild progression; in $30.0 \%$, the progression was moderate [ $>1$ to $\left.4 \mathrm{~mL} \cdot \min ^{-1} \cdot\left(1.73 \mathrm{~m}^{2}\right)^{-1}\right]$; and in $45.6 \%$, fast $[>4 \mathrm{~mL}$. $\left.\mathrm{min}^{-1} \cdot\left(1.73 \mathrm{~m}^{2}\right)^{-1}\right]$. Serum levels of uric acid of each group were $4.8 \pm 1.3,4.6 \pm 1.3,4.5 \pm 1.3$, and $4.5 \pm$ $1.3 \mathrm{mg} / \mathrm{dL}$, respectively, without statistically significant differences between groups. At the end of follow-up, 44 cases $(4 \%)$ exhibited eGFR $<60 \mathrm{~mL} \cdot \mathrm{min}^{-1} \cdot\left(1.73 \mathrm{~m}^{2}\right)^{-1}$.

To assess the association of selected parameters with the development of eGFR $<60 \mathrm{~mL} \cdot \mathrm{min}^{-1} \cdot\left(1.73 \mathrm{~m}^{2}\right)^{-1}$, we resorted to a multivariate logistic regression model (Table 2). Serum UA level, the variable of primary interest, was not found to be associated with the dependent variable. In fact, only female gender $(\mathrm{OR}=4.00 ; 95 \% \mathrm{Cl}=$ 1.92-8.29; $\mathrm{P}<0.001)$ and age, $(\mathrm{OR}=1.06$; 95\% $\mathrm{Cl}=1.02-$ $1.11 ; P=0.004)$ were statistically associated with the development of CKD. Serum HDL-C levels tended to be protective but statistical significance was not reached at the final analysis (OR=0.97; 95\% Cl=0.94-1.00; $\mathrm{P}=0.079)$.

To better understand the risk factors for progression of CKD in the study population, a second model of multivariate logistic regression was run using fast progression as the dependent variable (Table 3). Here, diabetes mellitus and BMI were found as independent factors for fast progression $(\mathrm{OR}=2.17 ; 95 \% \mathrm{Cl}=1.24-3.80, \mathrm{P}=0.007$, and $\mathrm{OR}=1.04 ; 95 \% \mathrm{Cl}=1.01-1.07 ; \mathrm{P}=0.020$, respectively).

\section{Discussion}

In this retrospective cohort study of Brazilian office workers, we investigated the association between asymptomatic hyperuricemia and new-onset CKD. At baseline, serum UA levels exhibited a weak but significant inverse correlation with eGFR. Along the study, 4 percent of the participants developed new-onset CKD, but asymptomatic hyperuricemia was not statistically associated with such endpoint. Indeed, in the multivariate analysis, the only factors associated with development of CKD were age and female gender, a finding consistent with a recent systematic review and meta-analysis addressing this subject (20). It should be commented that we did not find association of diabetes and hypertension with new-onset CKD. An absence of association of diabetes and newonset CKD had already been reported in two retrospective cohorts $(21,22)$. Characteristics of the study design could in part explain this apparent discrepancy. As participants with baseline eGFR $<60 \mathrm{~mL} \cdot \mathrm{min}^{-1} \cdot\left(1.73 \mathrm{~m}^{2}\right)^{-1}$ were excluded from the analysis, the follow-up period may not have been long enough to detect the development of CKD in patients with a high baseline eGFR. This subject was additionally explored in the second multivariate logistic regression model in which diabetes was confirmed as a strong independent factor associated with a fast progression rate. It should also be pointed out that an adequate control of diabetes and hypertension is well recognized as a factor that attenuates progression to CKD (10). In this regard, a large proportion of our hypertensive and diabetic patients was undergoing treatment and exhibited controlled blood pressure and glycemic status.

Despite several years of epidemiological and clinical research, the real significance of hyperuricemia as a predictor of CKD progression remains obscure. A number of 
Table 1. Baseline characteristics of participants.

\begin{tabular}{|c|c|c|c|c|}
\hline & All & HU- $(95.8 \%)$ & $\mathrm{HU}+(4.2 \%)$ & $P$ value \\
\hline $\mathrm{n}$ & 1094 & 1048 & 46 & - \\
\hline Male gender (\%) & $822(75.0 \%)$ & $787(75.1 \%)$ & $35(76.1 \%)$ & 0.879 \\
\hline Age (years) & $48.7 \pm 8.8$ & $48.7 \pm 8.9$ & $49.1 \pm 8.4$ & 0.774 \\
\hline White race $(\%)$ & $999(91.3 \%)$ & $958(91.4 \%)$ & $41(89.1 \%)$ & 0.751 \\
\hline Higher education (\%) & $659(60.2 \%)$ & $633(60.4 \%)$ & $26(56.5 \%)$ & $<0.001$ \\
\hline Sedentary lifestyle (\%) & $577(52.2 \%)$ & $541(51.6 \%)$ & $29(63.0 \%)$ & 0.129 \\
\hline Current smoker (\%) & $131(12 \%)$ & $128(12.2 \%)$ & $3(6.5 \%)$ & 0.244 \\
\hline BMI $\left(\mathrm{kg} / \mathrm{m}^{2}\right)$ & $27.1 \pm 4.6$ & $27.1 \pm 4.5$ & $29.9 \pm 5.5$ & $<0.001$ \\
\hline Systolic BP (mmHg) & $119.4 \pm 16.5$ & $119.1 \pm 16.4$ & $126.6 \pm 18.2$ & 0.002 \\
\hline Diastolic BP (mmHg) & $76.2 \pm 11.0$ & $76.0 \pm 11.0$ & $81.6 \pm 10.9$ & 0.001 \\
\hline Fasting plasma glucose (mg/dL) & $99.0 \pm 21.7$ & $98.8 \pm 21.9$ & $103.5 \pm 17.9$ & 0.154 \\
\hline Triglycerides (mg/dL) & $135.4 \pm 85.3$ & $132.2 \pm 83.6$ & $209.7 \pm 92.3$ & $<0.001$ \\
\hline Total cholesterol (mg/dL) & $202.0 \pm 37.2$ & $201.5 \pm 37.2$ & $214.6 \pm 37.6$ & 0.019 \\
\hline HDL-C (mg/dL) & $43.1 \pm 11.0$ & $43.3 \pm 11.0$ & $39.5 \pm 11.5$ & 0.023 \\
\hline \multicolumn{5}{|l|}{ Creatinine (mg/dL) } \\
\hline Male & $0.79 \pm 0.16$ & $0.78 \pm 0.16$ & $0.84 \pm 0.16$ & 0.036 \\
\hline Female & $0.62 \pm 0.17$ & $0.61 \pm 0.17$ & $0.69 \pm 0.16$ & 0.114 \\
\hline eGFR, $\mathrm{mL} \cdot \min ^{-1} \cdot\left(1.73 \mathrm{~m}^{2}\right)^{-1}$ & $105.6 \pm 14.8$ & $105.8 \pm 14.9$ & $100.2 \pm 14.1$ & 0.013 \\
\hline \multicolumn{5}{|l|}{ Uric acid (mg/dL) } \\
\hline Male & $4.9 \pm 1.2$ & $4.8 \pm 1.0$ & $7.7 \pm 0.6$ & $<0.001$ \\
\hline Female & $3.6 \pm 1.2$ & $3.5 \pm 1.0$ & $6.8 \pm 0.7$ & $<0.001$ \\
\hline Metabolic syndrome (\%) & $517(47.3 \%)$ & $477(45.5 \%)$ & $40(87 \%)$ & $<0.001$ \\
\hline Diabetes mellitus (\%) & $60(5.5 \%)$ & $56(5.3 \%)$ & $4(8.7 \%)$ & 0.328 \\
\hline Hypertension (\%) & $313(28.6 \%)$ & $294(28.1 \%)$ & $19(41.3 \%)$ & 0.052 \\
\hline
\end{tabular}

Data are reported as means $\pm \mathrm{SD}$, or number and \%. HU: hyperuricemia; BP: blood pressure; BMI: body mass index; HDL-C: highdensity lipoprotein cholesterol; eGFR: estimated glomerular filtration rate using CKD-EPI equation. Statistical analysis was done with the $t$-test and chi-square test or their non-parametric equivalent, as appropriate.

Table 2. Multivariate logistic regression model for predictors of development of glomerular filtration rate $<60 \mathrm{~mL} \cdot \mathrm{min}^{-1} \cdot\left(1.73 \mathrm{~m}^{2}\right)^{-1}$ at the end of follow-up.

\begin{tabular}{lccc}
\hline Predictive variables & OR & $95 \% \mathrm{Cl}$ & $\mathrm{P}$ \\
\hline Uric acid $(\mathrm{mg} / \mathrm{dL})$ & 1.12 & $0.83-1.50$ & 0.465 \\
Female gender & 4.00 & $1.92-8.29$ & 0.001 \\
Age (years) & 1.06 & $1.02-1.11$ & 0.004 \\
Diabetes mellitus & 0.79 & $0.18-3.55$ & 0.762 \\
Hypertension & 0.99 & $0.47-2.08$ & 0.980 \\
HDL-C (mg/dL) & 0.97 & $0.94-1.00$ & 0.079 \\
Triglycerides $(\mathrm{mg} / \mathrm{dL})$ & 1.00 & $0.99-1.00$ & 0.332 \\
BMI $\left(\mathrm{kg} / \mathrm{m}^{2}\right)$ & 0.98 & $0.90-1.06$ & 0.550 \\
Sedentary lifestyle & 0.95 & $0.51-1.79$ & 0.884 \\
Smoking & 0.93 & $0.37-2.29$ & 0.870 \\
\hline
\end{tabular}

OR: odds ratio; Cl: confidence interval; HDL-C: high-density lipoprotein cholesterol; BMI: body mass index.

studies have reported that UA is an independent risk factor for the development of kidney disease, while others have reported negative results (23-25). In a large
Table 3. Multivariate logistic regression model for predictors of fast progression along the follow-up.

\begin{tabular}{lccc}
\hline Predictive variables & OR & $95 \% \mathrm{Cl}$ & $\mathrm{P}$ \\
\hline Uric acid $(\mathrm{mg} / \mathrm{dL})$ & 0.90 & $0.81-1.01$ & 0.084 \\
Female gender & 0.84 & $0.61-1.17$ & 0.305 \\
Age (years) & 1.01 & $0.99-1.02$ & 0.403 \\
Diabetes mellitus & 2.17 & $1.24-3.80$ & 0.007 \\
Hypertension & 0.77 & $0.58-1.03$ & 0.076 \\
HDL-C $(\mathrm{mg} / \mathrm{dL})$ & 1.00 & $0.99-1.01$ & 0.766 \\
Triglycerides $(\mathrm{mg} / \mathrm{dL})$ & 1.00 & $0.99-1.00$ & 0.981 \\
BMl $\left(\mathrm{kg} / \mathrm{m}^{2}\right)$ & 1.04 & $1.01-1.07$ & 0.020 \\
Sedentary lifestyle & 0.92 & $0.72-1.17$ & 0.493 \\
Smoking & 0.76 & $0.52-1.12$ & 0.160 \\
\hline
\end{tabular}

OR: odds ratio; $\mathrm{Cl}$ : confidence interval; HDL-C: high-density lipoprotein cholesterol; BMI: body mass index.

retrospective cohort study of 94,422 Taiwanese participants, Wang et al. (26) demonstrated an independent link between hyperuricemia and incident CKD after 3.5 years of follow-up. Kawashima et al., in a retrospective cohort 
study of 1285 Japanese male workers, also found that asymptomatic hyperuricemia was a predictor of new-onset CKD after 18 years of follow-up (21). On the other hand, Chonchol et al. (27) in a cohort study of 5808 participants found that UA had a strong cross-sectional association with prevalent CKD and was a weak independent predictor of progression of kidney dysfunction. Yen et al. described similar results in a cohort study of 800 elderly Taiwanese subjects during a period of 2 years (28).

Some authors studied the relationship of hyperuricemia and long-term outcomes in patients with CKD. Madero et al. evaluated 838 patients with CKD stage 3 to 4 and found that hyperuricemia appeared to be an independent risk factor to all-cause mortality and cardiovascular mortality, but not kidney failure (29). In a recent study, Nacak et al. (30) concluded that UA is not associated with decline in renal function in a referred cohort of 2466 patients with stage 3, 4, and 5 CKD in Sweden.

Randomized controlled trials (RCT) evaluating the effects of UA lowering therapy on renal outcomes were reviewed in two meta-analysis. Zhang et al. reviewed seven RCT involving 451 cases and identified that UA lowering therapy could delay the progression of CKD (31). Otherwise, a meta-analysis of eight RCT evaluating 476 participants concluded that there was insufficient evidence to currently recommend widespread use of UA lowering therapy to slow the progression of CKD (32).

There are a number of mechanisms by which high levels of UA increases the risk for CKD development. In a study in rats, hyperuricemia increased systemic blood pressure, proteinuria, renal dysfunction, progressive renal scarring and induced vascular disease via a COX-2dependent pathway (33). Another study in hyperuricemic rats fed with a low-salt diet demonstrated glomerular hypertension, which appeared to be due to insufficient vasoconstriction of the afferent arteriole (34). There is clinical evidence that hyperuricemia is associated with hypertension due to endothelial dysfunction (35).

The understanding of the biological function of UA is far from elucidated. UA is recognized as a powerful antioxidant and is responsible for approximately half of the antioxidant capacity of human plasma. On the other hand, the molecule can also function as a pro-oxidant, either by generating free radicals during its degradation or by stimulating NADPH oxidase (36). Hyperuricemia results from interaction of several risk factors such as nutrition,

\section{References}

1. OJha V, Garcia-Garcia G, Iseki K, Li Z, Naicker S, Plattner $B$, et al. Chronic kidney disease: global dimension and perspectives. Lancet 2013; 382: 260-272, doi: 10.1016/ S0140-6736(13)60687-X.

2. Sesso RCC, Lopes AA, Thomé FS, Lugon JR, Watanabe $Y$, Santos DR. Report of the Brazilian Chronic Dialysis Census 2012. J Bras Nefrol 2014; 36: 48-53, doi: 10.5935/0101-2800.20150013. social-economic status, gender, age, genetic and environment, making its prevalence variable in different populations and areas. In the present study, which included a healthy, young and well-educated population, the prevalence of hyperuricemia was extremely low, affecting only $4.2 \%$ of the subjects, in contrast to $13.2 \%$ reported by Rodrigues et al. in a Brazilian population (37). The prevalence is higher in developed countries perhaps as a consequence of diet, sedentary lifestyle and an increase in obesity and hypertension, reaching $21.4 \%$ among US adults (38). In China, due to rapid economic changes, the prevalence is increasing and a meta-analysis found a rate of $13.3 \%$ (39). We could not find a definite explanation for the controversial findings about the role of UA as a predictor of new-onset CKD between studies.

Our study involved a relatively large sample. Participants had uniform access to health services and ease of follow-up, since the annual medical checkup was standardized. For legal reasons, medical records and laboratory results need to be kept for 20 years allowing precise monitoring. Nevertheless, some limitations must be considered. First, a single baseline measurement of UA was used to predict events several years later. However, a number of previous studies have resorted to the same approach. Second, the subjects were limited to employees of one company in Rio de Janeiro, predominantly composed of whites and not representative of the general Brazilian population. Third, the definition of renal progression was based on changes in eGFR, rather than more precise measurements of renal function, such as proteinuria or iothalamate clearance. Finally, the prevalence of hyperuricemia was very low in the cohort.

In conclusion, our findings indicate that UA had a weak, but significant, cross-sectional association with baseline eGFR and was not correlated with new-onset CKD in a specific group of Brazilian workers. These results did not support UA as an independent predictor for CKD progression in the studied population. The question of whether a study addressing poorer segments of the Brazilian population would lead to a similar conclusion should be investigated.

\section{Acknowledgements}

We are in debt to Dr. Eduardo Nunes Chini for his valuable help regarding the final review of the manuscript.

3. K/DOQI clinical practice guidelines for chronic kidney disease: evaluation, classification and stratification. $A m \mathrm{~J}$ Kidney Dis 2002; 39: S1-S246.

4. Bastos MG, Carmo WB, Abrita RR, Almeida EC, Mafra D, Costa DMN, et al. Chronic kidney disease: problems and solutions. J Bras Nefrol 2004; 26: 202-15, doi: 10.5935/ 0101-2800.20150013. 
5. Bakris GL, Williams M, Dworkin L, Elliott WJ, Epstein $M$, Toto $R$, et al. Preserving renal function in adults with hypertension and diabetes: a consensus approach. National Kidney Foundation Hypertension and Diabetes Executive Committees Working Group. Am J Kidney Dis 2000; 36: 646-661, doi: 10.1053/ajkd.2000.16225.

6. Yamagata K, Ishida K, Sairenchi T, Takahashi H, Ohba S, Shiigai $\mathrm{T}$, et al. Risk factors for chronic kidney disease in a community-based population: a 10-year follow-up study. Kidney Int 2007; 71: 159-166, doi: 10.1038/sj.ki.5002017.

7. Rymal E, Rizzolo D. Gout: a comprehensive review. JAAPA 2014; 27: 26-31, doi: 10.1097/01.JAA.0000453233.24754.ec.

8. Wang J, Qin T, Chen J, Li Y, Wang L, Huang H, et al. Hyperuricemia and risk of incident hypertension: a systematic review and meta-analysis of observational studies. PLOS One 2014; 9: e114259, doi: 10.1155/2014/852954.

9. Feig DI, Kang DH, Johnson RJ. Uric acid and cardiovascular risk. N Engl J Med 2008; 359: 1811-1812, doi: 10.1056/ NEJMra0800885.

10. KDIGO 2012 Clinical Practice Guideline for the Evaluation and Management of Chronic Kidney Disease. Kidney Int 2013; 3: 1-150, doi: 10.1038/kisup.2012.73.

11. Feig DI. Uric acid: a novel mediator and marker of risk in chronic kidney disease? Curr Opin Nephrol Hypertens 2009; 18: 526-530, doi: 10.1097/MNH.0b013e328330d9d0.

12. Zhu P, Liu Y, Han L, Xu G, Ran JM. Serum uric acid is associated with incident chronic kidney disease in middleaged populations: a meta-analysis of 15 cohort studies. PLoS One 2014; 9: e100801, doi: 10.1371/journal.pone. 0100801.

13. L Li, C Yang, $Y$ Zhao, $X$ Zeng, $F$ Liu, $P$ Fu. Is hyperuricemia an independent risk factor for new-onset chronic kidney disease? A systematic review and meta-analysis based on observational cohort studies. BMC Nephrol 2014; 15: 122, doi: 10.1186/1471-2369-15-122.

14. Dousdampanis P, Trigka K, Musso CG, Fourtounas C. Hyperuricemia and chronic kidney disease: an enigma yet to be solved. Ren Fail 2014; 36: 1351-1359, doi: 10.1186/ 1471-2369-15-122.

15. Lin CS, Hung YJ, Chen GY, Tzeng TF, Lee DY, Chen CY, et al. A multicenter study of the association of serum uric acid, serum creatinine, and diuretic use in hypertensive patients. Int J Cardiol 2011; 148: 325-330, doi: 10.1016/ j.ijcard.2009.11.024.

16. Levey AS, Stevens LA, Schmid CH, Zhang YL, Castro AF 3rd, Feldman $\mathrm{HI}$, et al. A new equation to estimate glomerular filtration rate. Ann Intern Med 2009; 150: 604612, doi: 10.7326/0003-4819-150-9-200905050-00006.

17. Aram VC, George LB, Henry RB, William CC, Lee AG, Joseph LI Jr and the National High Blood Pressure Education Program Coordinating Committee. The Seventh Report of the Joint National Committee on Prevention, Detection, Evaluation, and Treatment of High Blood Pressure. JAMA 2003; 289: 2560-2571, doi: 10.1161/01.HYP.0000107251. 49515.c2.

18. World Health Organization. Definition and diagnosis of diabetes mellitus and intermediate hyperglycemia. Report of a WHO/IDF Consultation. Geneve: World Health Organization; 2006.

19. Alberti KG, Eckel RH, Grundy SM, Zimmet PZ, Cleeman JI, Donato $\mathrm{KA}$, et al. Harmonizing the metabolic syndrome.
A joint interim statement of the International Diabetes Federation task force on epidemiology and prevention; National Heart, Lung and Blood Institute; American Heart Association; World Heart Federation; International Atherosclerosis Society; and International Association for the study of Obesity. Circulation 2009; 120: 1640-1645, doi: 10.1161/ circulationaha.109.192644.

20. Hill NR, Fatoba ST, Oke JL, Hirst JA, O'Callaghan CA, Lasserson DS et al. Global prevalence of chronic kidney disease - a systematic review and meta-analysis. PLoS One 2016; 11: e0158765, doi: 10.1371/journal.pone.0158765.

21. Kawashima M, Wada K, Ohta H, Terawaki H, Aizawa $Y$. Association between asymptomatic hyperuricemia and newonset chronic kidney disease in Japanese male workers: a long-term retrospective cohort study. BMC Nephrol 2011; 12: 12, doi: 10.1186/1471-2369-12-31.

22. Yamagata K, Ishida K, Sairenchi T, Takahashi H, Ohba S, Shiigai $\mathrm{T}$ et al. Risk factors for chronic kidney disease in a community-based population: a 10-year follow-up study. Kidney Int 2007; 71: 159-166, doi: 10.1038/sj.ki.5002017.

23. Obermayr RP, Temml C, Gutjahr G, Knechtelsdorfer M, Oberbauer R, Klauser-Braun R. Elevated uric acid increases the risk for kidney disease. J Am Soc Nephrol 2008; 19: 2407-2413, doi: 10.1681/ASN.2008010080.

24. Bellomo G, Venanzi S, Verdura C, Saronio P, Esposito A, Timio M. Association of uric acid with change in kidney function in healthy normotensive individuals. Am J Kidney Dis 2010; 56: 264-272, doi: 10.1053/j.ajkd.2010.01.019.

25. Sturm G, Kollerits B, Neyer U, Ritz E, Kronenberg F; MMKD Study Group. Uric acid as a risk factor for progression of non-diabetic chronic kidney disease? The Mild to Moderate Kidney Disease (MMKD) Study. Exp Gerontol 2008; 43: 347-352, doi: 10.1016/j.exger.2008.01.006.

26. Wang S, Shu Z, Tao Q, Yu C, Zhan S, Li L. Uric acid and incident chronic kidney disease in a large health check-up population in Taiwan. Nephrology 2011; 16: 767-776, doi: 10.1111/j.1440-1797.2011.01513.x.

27. Chonchol M, Shlipak MG, Katz R, Sarnak MJ, Newman AB, Siscovick DS et al. Relationship of uric acid with progression of kidney disease. Am J Kidney Dis 2007; 50: 239-247, doi: 10.1053/j.ajkd.2007.05.013.

28. Yen CJ, Chiang CK, Ho LC, Hsu SH, Hung KY, Wu KD, et al. Hyperuricemia associated with rapid renal function decline in elderly Taiwanese subjects. J Formos Med Assoc 2009; 108: 921-928, doi: 10.1016/S0929-6646(10)60004-6.

29. Madero M, Sarnak MJ, Wang X, Greene T, Beck GJ, Kusek $\mathrm{JW}$, et al. Uric acid and long-term outcomes in CKD. Am J Kidney Dis 2009; 53: 796-803, doi: 10.1053/j.ajkd.2008.12.021.

30. Nacak H, van Diepen M, Qureshi AR, Carrero JJ, Stijnen T, Dekker FW, et al. Uric acid is not associated with decline in renal function or time to renal replacement therapy initiation in a referred cohort of patients with Stage III, IV and V chronic kidney disease. Nephrol Dial Transplant 2015; 30: 2039-2045, doi: 10.1093/ndt/gfv225.

31. Zhang YF, He F, Ding HH, Dai W, Zhang Q, Luan $H$, et al. Effect of uric-acid-lowering therapy on progression of chronic kidney disease: a meta-analysis. J Huazhong Univ Sci Technolog Med Sci 2014; 34: 476-481, doi: 10.1007/ s11596-014-1302-4.

32. Bose B, Badve SV, Hiremath SS, Boudville N, Brown FG, Cass $A$, et al. Effects of uric acid-lowering therapy on renal 
outcomes: a systematic review and meta-analysis. Nephrol Dial Transplant 2014; 29: 406-413, doi: 10.1093/ndt/gft378.

33. Kang DH, Nakagawa T, Feng L, Watanabe S, Han L, Mazzali $\mathrm{M}$, et al. A role for uric acid in the progression of renal disease. J Am Soc Nephrol 2002; 13: 2888-2897, doi: 10.1097/01.ASN.0000034910.58454.FD.

34. Sánchez-Lozada LG, Tapia E, Avila-Casado C, Soto V, Franco M, Santamaría J, et al. Mild hyperuricemia induces glomerular hypertension in normal rats. Am J Physiol Renal Physiol 2002; 283: 1105-1110, doi: 10.1152/ajprenal.00170. 2002.

35. Zoccali C, Maio R, Mallamaci F, Sesti G, Perticone F. Uric acid and endothelial dysfunction in essential hypertension. J Am Soc Nephro 2006; 17: 1466-1471, doi: 10.1681/ASN. 2005090949.
36. So A, Thorens B. Uric acid transport and disease. J Clin Invest 2010; 120: 1791-1799, doi: 10.1172/JCI42344.

37. Rodrigues SL, Baldo MP, Capingana DP, Magalhães $P$, Dantas EM, Molina M del CB, et al. Gender Distribution of serum uric acid and cardiovascular riskfactors: population based study. Arq Bras Cardiol 2012; 98: 13-21, doi: 10.1590/ S0066-782X2011005000116.

38. Zhu Y, Pandya BJ, Choi HK. Prevalence of gout and hyperuricemia in the US general population: the National Health and Nutrition Examination Survey 2007-2008. Arthritis Rheum 2011; 63: 3136-3141, doi: 10.1002/art.30520.

39. Liu R, Han C, Wu D, Xia X, Gu J, Guan H et al. Prevalence of hyperuricemia and gout in Mainland China from 2000 to 2014: A systematic review and meta-analysis. BioMed Res Int 2015. Article ID 762820, doi: 10.1155/2015/762820. 